$\mathrm{V}, \mathrm{K} \mathrm{K} 314.15$

ББК 60.74

DOI 10.22394/1682-2358-2021-4-107-118

M.V. Romanova, master's student at the Public Administration Department, Siberian Institute of Management, Branch of the Russian Presidential Academy of National Economy and Public Administration

\section{MIGRATION POLICY OF MODERN RUSSIA: INTERNAL ASPECTS}

The main aspects of the migration policy of Russia are analyzed. The main goals of the state migration policy of the Russian Federation for the period up to 2025 are highlighted. The main shortcomings of modern migration policy are identified. Basic aspects hindering dynamic development of migration processes in Russia are studied. Based on the available data, three main directions for the development of those processes that would allow attracting a larger number of migrants are proposed.

Key words and word-combinations: migration policy, labor migration, international migration.
М.В. Романова, махистрант кафедрь государственного и мунииипального управления Сибирского института управления - филиала Российской академии народного хозяйства и государственной службь при Президенте РФ (етаil: romanova-m»@ranepa.ru)

\section{МИГРАЦИОННАЯ ПОАИТИКА СОВРЕМЕННОЙ РОССИИ: ВНУТРЕННИЕ АСПЕКТЫ}

\footnotetext{
Аннотация. Анализируются основные аспекты миграционной политики России. Выделены главные цели государственной миграционной политики Российской Федерации на период до 2025 г. Исследуются негативные аспекты, препятствующие активному развитию миграционных процессов в России. Предложены три основных направления развития процессов, которые позволят привлечь большее число мигрантов.

Ключевые слова и словосочетания: миграционная политика, трудовая миграция, международная миграция.
}

$M$ аужнй составмяюшей социамьно-экономической политики. Она способствует развитию рыночных отношений, обеспечению человеческими ресурсами рынка труда, повышению конкурентоспособности государства. Последние Аесятилетия характеризуются активным ростом миграционных потоков, что требует совершенствования миграционной политики в соответствии с современными тенденциями. Разработка 
новой миграционной политики государства позволит решать проблемы не только мигрантов, но и в близких сферах бизнеса, что, в свою очередь, окажет положительное влияние на экономическую ситуацию в стране.

Теоретический и практический интерес преАставцяет анациз отечественного опыта миграџионной политики. При разработке современной миграционной политики изучение прошлого позволит определить, какие процессы привлекают потоки мигрантов, являющихся «полезными» дмя страны, какие механизмы реацизации данной политики смедует усовершенствовать, а какие искмючить. Кроме того, необходимо выявить социально-экономические аспекты, способствующие или препятствующие развитию трудовой миграции. Это прежде всего уровень жкизни населения, размер заработной платы, сфера образования, медицины и Аругие факторы.

Определение основных направлений совершенствования современной миграционной политики в России явцяется актуальной научной проблемой. Исследователями ведутся дискуссии, связанные с выявлением направления развития миграционного законодательства с учетом интересов как принимающей стороны, так и мигрантов, ориентированных на более облегченную интеграцию в российском обществе. Результаты анализа миграционной политики послеАних мет позволяют выявить основные недостатки в проџессе ее применения. Изучение статистических данных отечественного рынка труда свидетельствует о том, что с позиции экономического подхода использование рабочей силы стран-доноров способствует росту населения России, повышению производительности труда, снижению финансовой нагрузки за счет установления более низкой заработной платы. ОАнако при разработке мер миграционной политики следует учитывать интересы населения страны-реципиента: желаемый уровень дохода, качество жизни и отношения местного населения к мигрантам.

Таким образом, на основе опыта развития миграционной политики в России следует рассматривать каждую меру как с точки зрения мигрантов, так и со стороны местного населения, учитывая при этом все неАостатки с целью дальнейшего их устранения и Аостоинств - Аля совершенствования законодательства.

Теоретической базой исследования явились Конџепџия государственной миграционной политики Российской Федерации на периоА до 2025 г. и Прогноз социально-экономического развития Российской Федерации на период до 2036 г. В качестве источника основных концепций и подходов формирования миграционной политики использо- 
вались работы В.А. Волоха $[1 ; 2]$. Миграция как явление рассмотрена в нормативно-правовом и социокультурном аспектах. Проанализированы проблемы миграционной политики Российской Федерации в контексте вопросов прав человека и гражданина.

В соответствии с Конџепџией государственной миграционной политики Российской Федераџии на период до 2025 г. [3] миграционная политика проводится Аля Аостижения следующих цемей:

- обеспечения национальной безопасности Российской Федерации и благопомучия насемения;

- увеличения численности постоянного населения Российской Федерации;

- помощи в обеспечении экономики страны в рабочей силе, повышении конкурентоспособности ее отраслей.

Несмотря на то что џели Конџепџии преАполагают ее положительное влияние на граждан страны и соџиально-экономическое развитие, в реальности ситуация скмадывается несколько иначе. В научных исследованиях таких авторов, как В.Ю. Зорин, М.А. Бурда [4], К.В. Аршин [5] , К.В. Боричев, М.Ю. Павлик [6], отмечается нацичие взаимосвязи миграџионных потоков с ростом преступности, существование проблем незаконной мигращии, обострение конфликтов на национацьной почве, консервативное отношение местного насемения к процессу миграџии, что подтверждается и статистическими Аанными послеАних мет.

По сведениям портала правовой статистики [7], миц, совершивших преступления в период 2019-2021 гг., среди мигрантов 3\%. Если учитывать, что Аоля мигрантов в России по состоянию на 2021 г. составмяет 20\%, этот уровень преступности весьма высок. Приведенные Аанные противоречат одной из основных цемей Концепции - обеспечение национальной безопасности Российской Федерации и благополучия граждан.

Неоднозначно оценивается и ситуация в сфере обеспечения рабочей силой. В 2020 г. в связи с пандемией и закрытием граниџ количество трудовых мигрантов сократилось практически в Ава раза (с 14,9 до 7,5 млн чел. [8] ), вслеАствие чего снизилось количество работников в строительстве, на транспорте, низкоквалифицированных работах. Граждане России не желают занимать вакантные места в связи с низким уровнем заработной платы. Именно поэтому, несмотря на увеличение количества вакансий на рынке труда, в стране отмечается достаточно высокий уровень безработицы - 6,1\% [9] (в начаме 2020 г. - 4,7\%). Авторы работы «Вцияние пандемии COVID-19 на положкение мигрантов на 
рынках труда стран СНГ» считают, что ограничительные меры в 2020 г. привели не только к падению уровня экономики, но и к росту безработиџы и переходу многих законных мигрантов к статусу нелегальных, несмотря на либерализацию российского законодательства в указанный период [10].

Согласно экспертным оценкам, вместо того чтобы искать пути привлечения трудовых мигрантов в страну, целесообразно повышать заработную плату на низкоквалифицированных должностях и создавать такие рабочие условия, чтобы граждане России могли здесь трудиться и получать Аостойную заработную плату. Человеческие ресурсы Аля этого в стране имеются в достаточном объеме, и заполнение рабочих мест не станет проблемой. Необходимо разработать систему, которая позволит в короткие сроки переквалифицировать работников Аля успешного осуществления трудовой деятельности в таких отраслях, как сельское хозяйство, строительство и т.А. М.А. Галас, описывая политические и социальные риски иммиграционных потоков дия России, обращает внимание на нововведения в миграционном законодательстве, связанные с ростом напряженности в некоторых странах, что ведет к напряжению на российском рынке занятости. Он отмечает что «сохраняется неравномерность распределения законных иммигрантов по регионам России... <...> Уровень безработиџы в одной из основных стран - миграционных доноров - Таджикистане бым вполовину ниже по сравнению с Россией, равно как и в Киргизии...» [11]. Несмотря на то что уровень безработиџы в России выше, чем в странах-донорах, мигранты продолжают прибывать в страну, что чревато ростом неработающего населения и усилением соџиальной напряженности.

Увеличение численности населения за счет мигрантов - тоже спорный вопрос. На граждан накладывается высокая налоговая нагрузка. Помимо прямых налогов (НАФ $\Lambda$, налог на имущество, транспортный налог и т.А.), гражАане дополнительно косвенно платят НАС, акцизы и иное, так как эти налоги накладываются на конечного потребителя. Работодатель также оплачивает за работника страховые взносы $-30 \%$. Все эти отчисления распределяются по различным уровням бюджета на социальное обеспечение (пособия, цьготы и т.А.) не только граждан, родившихся в стране и плативших налоги, но и мигрантов, которые приезжают в Россию и становятся многодетными семьями. Такая категория граждан создает высокую нагрузку на бюджет. С одной стороны, численность населения растет, с Аругой стороны, растут и расходы на соџиальную поддержку такого населения.

Необходимо пересматривать и основные цели миграционной по- 
митики, зафиксированные в Концепции, так как в последние годы ситуация не улучшается, а в некоторых случаях в связи с известными событиями даже становится значительно хуже.

Нуждается в детальном изучении и вопрос миграции российских гражАан из страны. Опредемяющими причинами этого проџесса явмяется следующее.

Во-первых, низкий уровень заработной платы, точнее, низкий уровень оплаты труда по отношению к производительности, что отмечается многими исследователями. По мнению В.И. Жмачинского, «ситуация усугубцяется такими явлениями, как зарплаты в конвертах и неофициальная занятость» [12]. Это одна из ключевых причин, по которой граждане России стремятся мигрировать в другие страны, где оплата труда выше и отсутствует теневая занятость. Именно поэтому и квалифицированная рабочая сила из-за рубежа не перетекает в Россию Амя установления трудовых отношений.

По официальным данным Федеральной службы государственной статистики, среднемесячная номинальная начисленная заработная плата работников в целом по экономике Российской Федерации за 2019 г. составила 47867 руб. (627 Аом..), за 2020 г. (преАварительно) - 51083 руб. (669 Аом..). Аля сравнения приведем годовую заработную плату в Аоммарах: за 2019 г. среАний российский гражАанин заработал 7524 дом., За 2020 г. - 8028 дом. В странах, куда чаще всего стремятся граждане России, аналогичные показатели приведены в таблице.

Средний уровень заработной пматы по странам

\begin{tabular}{c|c|c}
\hline \multirow{2}{*}{ Страна } & \multicolumn{2}{|c}{ Уровень заработной платы, по годам, долл. США } \\
\cline { 1 - 3 } & 2019 & 2020 \\
\hline Канада [13] & 42594 & 43463 \\
США [14] & 48672 & 47052 \\
Австралия [15] & 43020 & 40152 \\
Новая Зеландия [15] & 42912 & 40248 \\
Швейцария [15] & 75240 & 74928
\end{tabular}

Таким образом, средняя заработная пиата в России ниже, чем в перечисленных странах, примерно в 6,4 раза; в Швейцарии заработная плата выше в десять раз [15]. Помимо заработной платы, которая не является абсолютным показателем высокого уровня жизни (необхоАимо учитывать налоги, цены и т.А.), у каждой страны имеется так 
называемый индекс человеческого развития (ИЧР). Перечисленные страны обладают высоким ИЧР $(0,91-0,96)$ [16] ) и входят в первые Авадцать развитых стран мира. Россия занимает 52-е место, ее показатель составмяет 0,824 .

Во-вторых, высокий уровень безработиџы, который в середине 2020 г., по данным Федеральной служббы государственной статистики, достиг 6,1\% [9]. Такой фактор, как пандемия, показац несостоятельность российской сферы малого и среАнего предпринимательства, так как именно эта сфера дает наибольшее число рабочих мест - Аоля малых и среАних преАприятий 73,4\% [17] по состоянию на август 2020 г. В основном это сфера торговли и услуг. Из-за объявленного режима самоизоляции компании были вынуждены закрываться и увольнять своих работников.

Таким образом, небольшой диапазон сфер и должностей, в которых может работать российский гражданин, не оставцяет шансов на перспективы карьерного роста, высокий уровень заработной платы и высокий уровень качества жкизни.

В-третьих, неравномерное расселение граждан по регионам России влечет за собой неравномерное распределение уровня качества жизни. На диаграмме (рис. 1) демонстрируется соотношение комичества жителей восьми субъектов Федерации, которые по численности населения явцяются самыми крупными в своем федеральном округе.

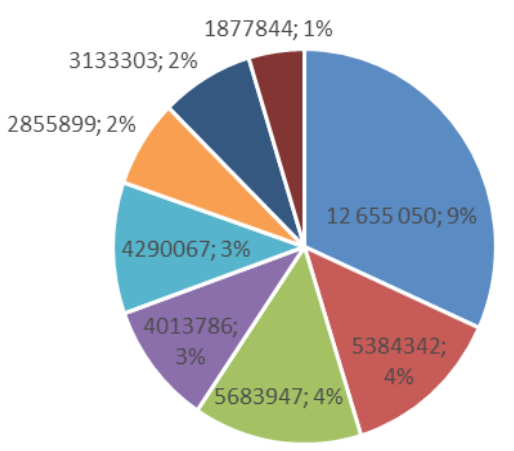

$$
\begin{aligned}
& \text { - г Москва - г. Санкт-Петербург = Краснодарский край - р. Башкортостан } \\
& \text { - Свердловская область = Красноярский край - р. Дагестан - Приморский край }
\end{aligned}
$$

Рис. 1. Аоля численности населения по субъектам Федерации по состоянию на 1 января 2021 г. 
Из рис. 1 следует, что 13\% всей численности России, более 18 млн человек, проживают в двух городах - Москве и Санкт-Петербурге, что создает высокую нагрузку на дорожную сеть, инфраструктур и т.А. Вместе с тем этот факт свидетельствует о неравномерном распреАелении уровня качества жкизни по регионам. Проимлюстрируем это Аанными за 2020 г., приведенными на рис. 2 [18] .

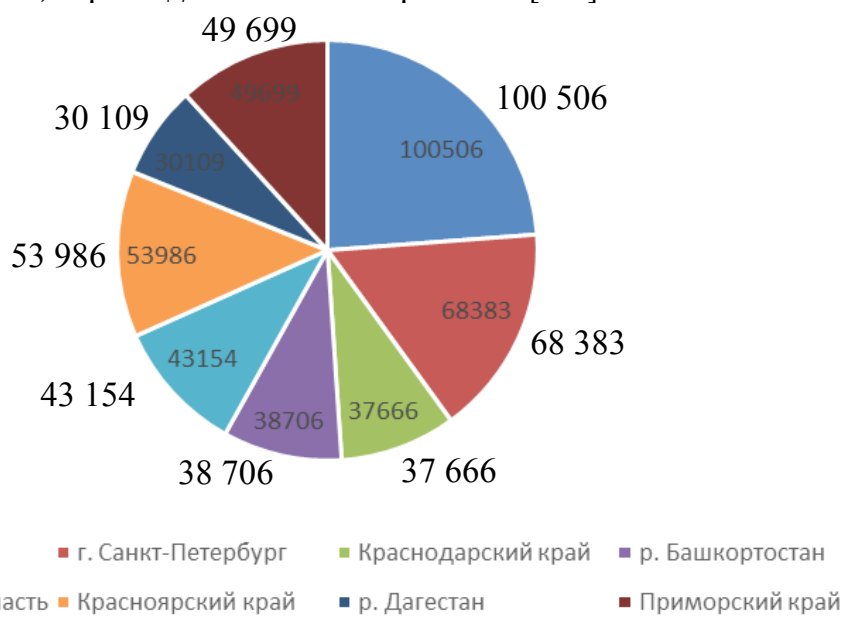

\section{Рис. 2. Среднемесячная заработная пиата по субъектам Федерации за 2020 г.}

По причине значительного разрыва в уровне заработной пиаты межку Москвой, Санкт-Петербургом и другими крупными субъектами РФ многие граждане стремятся переехать в эти два города, что, в свою очередь, перегружает их, так как инфраструктура не рассчитана на такое количество жителей. Категория мюдей, желающих иметь высокую заработную и комфортную жизнь, как правицо, покидают страну.

В контексте миграционных процессов России аргументом в пользу низкой заработной платы является показатель Федеральной службы государственной статистики по среднемесячной номинальной начисменной заработной плате работников по полному кругу организаций по видам экономической деятельности, который с 2019 по третий квартал 2020 г. вырос на 1532 руб. [19], то есть на 3,19\%. Вместе с тем официальный уровень инфмяции в стране на конец 2020 г. составил 4,91\% [20]. Следовательно, повышение заработной платы не позволиц покрыть текущий официальный уровень инфмяции в России. 
Низкий рост заработной платы можно объяснить также наличием большого количества трудовых мигрантов из стран, уровень жизни и доходов которых ниже, чем в России. По статистике, за 2019 г. в Россию из зарубежных стран прибыли 701234 чел. [8]. Таким трудовым мигрантам выгодно приезжкать в Россию и получать заработную плату выше по меркам их родных стран, но намного ниже уровня, который считается достойным Амя россиян. Поток подобных трудовых мигрантов снижает стоимость оплаты труда работников даже высокой квалификации.

Привлечение иностранных работников явцяется одним из источников увеличения численности населения, однако при разработке мер Аля привлечения трудовых мигрантов из зарубежных стран должны учитываться уровень заработной платы и трудовая статистика страны, в которую привлекаются мигранты.

Вопрос граждан, которые желают мигрировать из России в другие страны, требует особого изучения. Необходимо понять, почему Аюди стремятся за рубеж, чего им не хватает Аля достойной жизни в своей стране. Повышение уровня заработной платы следует координировать с реформированием миграционной политики.

Слабость российской сырьевой экономики опредемяется ее зависимостью от иностранной валюты. По итогам 2020 г., в котором была не только пандемия, но и падение спроса на нефть, в России произошио снижение ВВП на 3,1\% [21]. Если анализировать по отраслям, то прежде всего наблюдается сокращение прибыли в сфере обслуживания населения, что объясняется карантинными мерами. Падение цен на нефть, снижение спроса на нефтепродукты привело к обесцениванию рубля, падению реальных доходов населения и росту цен, что, в свою очередь, стало причиной смещения структуры потребления в пользу продовольствия. В результате граждане отказались от принятия долгосрочных решений в силу нестабильности ситуации в сфере экономики и финансов.

Низкий уровень качества медицины в России вследствие ее неАостаточного финансирования, дефицита кадров, повышения нагрузки на медиџинский персонац, неравенства в доступе к медиџинской помощи наглядно был продемонстрирован в острой ситуаџия 2020 г. Помимо высокой смертности от коронавирусной инфекции, выросла смертность от Аругих заболеваний, так как все силы медицинского персонала были брошены на преодоление пандемии, а мечение остальных заболеваний осталось не в приоритете.

Существенной проблемой остается неравномерное распределение средств бюджета по регионам. Более обеспеченные субъекты (города 
федерального значения) получают медицинские услуги в достаточном количестве и в короткие сроки, а в регионах нет даже необходимого оборудования дмя оказания медицинской помощи и проведения обследований. Слабая медицина является одной из основных причин, по которой граждане предпочитают переезжать в Аругие страны, где эта проблема решена.

Все перечисленные факторы ведут к тому, что Россия может стать страной, которая теряет качественные квалифицированные кадры и принимает к себе низкоквалифицированную рабочую силу. Чтобы этого не Аопустить, необходимо совершенствовать не только соџиальную и экономическую политику внутри государства, но и миграционную политику, так как от нее в немалой степени зависит уровень заработной платы по отраслям, количество рабочих мест, а следовательно, и качество жизни. Целесообразно создавать привлекательную атмосферу Аля той категории мигрантов, которая может принести пользу не в качестве дешевой рабочей силы, а в качестве инвестиций, своего рода интемлектуального ресурса Аля Аальнейшего развития страны. Нельзя выстраивать миграционную политику в ущерб своим гражданам исключительно на основе исторических и геополитических связей; опыт показывает, что благосостояние населения от таких шагов не растет, а ситуаџия на рынке труда и в экономике в целом не становится иучше.

В настоящее время мигранты являются уязвимой категорией - в большинстве случаев работают незаконно, не могут рассчитывать на государственную подАержку, мьготы и пособия, поэтому следует разработать систему соџиальной защиты мигрантов, выводить их на официальное трудоустройство. Аанная мера позволит увеличить объем поступлений в бюАжеты за счет отчислений и повысить конкурентоспособность страны Аля мигрантов. В Аействующем миграционном законодательстве прописаны нормы, имеющие преимущества Аля высококвацифицированных мигрантов (налоговая ставка в соответствии с режимом налогового резидента Российской Федераџии,, увеличенный Ао трех мет срок разрешения на работу и т.п., но мигрантов необходимо привлекать стабильной экономической ситуацией в стране и высоким уровнем жиини.

ОАнако, помимо соџиальных гарантий, Россия в своей миграционной политике должна разработать систему критериев, по которым организация имеет право нанимать к себе мигрантов. Сегодня имеется система квотирования: в 2020 г. квота составмяла 104993 чел. [22] - предпомагаемое количество работников из стран, где требуется приглашение на въезА в Россию. Что касается «безвизовых» стран, то здесь сушествует 
лишь ограничение иностранной рабочей силы по отраслям. Такая мера неэффективна в вопросе регулирования рынка труда, так как нет системы, позволяющей доказать, что среди местных соискателей нет работника Аолжной квалификации и имеется необходимость нанять мигранта на должность. Следовательно, мигранты занимают вакансии, а российские гражкане остаются без работы.

Нанимая квалифицированную рабочую силу через особую систему отбора кадров, учитывая экономическую ситуацию и уровень безработиџы в стране, появится возможность не только учитывать интересы российских граждан, но и модернизировать различные сферы экономики за счет притока иностранной рабочей силы, которая обладает Аолжной квалификаџией и сможет делиться своими знаниями и опытом Аля развития организаций. В свою очередь, высококвалифицированные мигранты будут держать достаточно высокий уровень заработной платы, что заставит работодателей не занижать заработную плату по вакансиям.

В џелом результаты исследования показывают, что в России немало социально-экономических факторов, которые не только не привлекают квалифицированную рабочую силу в страну, но и создают риск потери ценных кадров из числа граждан [23]. Ситуацию способно исправить совершенствование миграционной политики, вкАючающей разработку системы гарантий Аця потенциальных мигрантов, смягчение процедуры миграции дмя высококвалифицированных рабочих, а также улучшение экономической ситуации в стране, что может привлечь мигрантов из развитых стран. Вместе с тем необходимо собмюсти интересы граждан России: обеспечить спокойную криминогенную обстановку, мигрантов занимать работой не в ущерб местному насемению [24].

Решению миграционной проблемы в России будет способствовать создание единой трудовой базы мигрантов, содержащей все необходимые данные, включая показатели квалификации и опыта работы мигранта. Такая мера является положительной и для самих мигрантов: им при наличии данных в базе можно обращаться в центр занятости, например, при потере имеющейся работы и подыскивать необходимую вакансию. ЕАиная база мигрантов также позволит сократить поток нелегальных мигрантов, в основном тех, кого уже депортироваци из страны. При сборе биометрических данных можно отслеживать перемещение мигрантов по стране дажке при смене первоначальных параметров.

Совершенствование миграционной политики по перечисленным направлениям позволит внести положительные изменения в процесс трудоустройства и мигрантов, и российских гражАан. 


\section{Библиографический список}

1. Волох В.А., Герасимова И.В. Управление миграционными процессами в Российской Федерации: анализ и перспективы // Управление. 2019. № 1. URL: https:// cyberleninka.ru/article/n/upravlenie-migratsionnymi-protsessami-v-rossiyskoy-federatsiianaliz-i-perspektivy.

2. Волох B.A. Новая Россия: политика и управление миграционными процессами. Самара, 2015.

3. Концепция государственной миграционной политики Российской Федерации на период до 2025 года. URL: http://kremlin.ru/events/president/news/15635.

4. Зорин В.Ю., Бурда М.А. Формирование и институционализация государственной миграционной политики в современной России // PolitBook. 2020. № 1. URL: https://cyberleninka.ru/article/n/formirovanie-i-institutsionalizatsiya-gosudarstvennoymigratsionnoy-politiki-v-sovremennoy-rossii

5. Аршин К.В. Диалектика секьюритизации и либерализации в миграционной политике России // Власть. 2019. № 2. URL: https://cyberleninka.ru/article/n/dialektikasekyuritizatsii-i-liberalizatsii-v-migratsionnoy-politike-rossii

6. Боричев К.В., Павлик М.Ю. О причастности трудовых мигрантов - выходцев из стран Центральной Азии - к террористической деятельности // Вестник СанктПетербургского университета МВД России. 2019. № 4 (84). URL: https://cyberleninka. ru/article/n/o-prichastnosti-trudovyh-migrantov-vyhodtsev-iz-stran-tsentralnoy-azii-k-terroristicheskoy-deyatelnosti

7. Статистика по преступлениям // Портал правовой статистики. URL: http:// crimestat.ru/offenses map

8. Динамика движения населения. URL: https://rosstat.gov.ru/folder/12781

9. Занятость и безработица в Российской Федерации в январе 2021 года. URL: https://gks.ru/bgd/free/B04_03/IssWWW.exe/Stg/d02/38.htm

10. Рязанцев С.В., Молодикова И.Н., Брагин А.Д. Влияние пандемии COVID-19 на положение мигрантов на рынках труда стран СНГ // Балтийский регион. 2020. Т. 12, № 4. C. 10-38. URL: https://cyberleninka.ru/article/n/vliyanie-pandemii-covid-19-napolozhenie-migrantov-na-rynkah-truda-stran-sng

11. Галас М.Л. Политические и социальные риски иммиграционных потоков для России // Гуманитарные науки. Вестник Финансового университета. 2020. № 2. URL: https://cyberleninka.ru/article/n/politicheskie-i-sotsialnye-riski-immigratsionnyh-potokov-dlya-rossii

12. Жмачинский В.И., Чернева Р.И. Производительность труда, заработная плата и уровень жизни: проблемы повышения и перспективы // Экономический анализ: теория и практика. 2019. № 1 (484). URL: https://cyberleninka.ru/article/n/proizvoditelnost-truda-zarabotnaya-plata-i-uroven-zhizni-problemy-povysheniya-i-perspektivy

13. Уровень средней заработной платы в Канаде. URL: https://www.jobbank.gc.ca/ home

14. Зарплата в США. URL: https://meet-usa.com/ru/article/zarplata-v-ssha/

15. Насколько хорошо за границей, или Средние зарплаты в мире. URL: https:// visasam.ru/emigration/vybor/srednya-zarplata-v-mire.html

16. Индекс человеческого развития (ИЧР). URL: https://nonews.co/directory/lists/ countries/index-human 
17. В России сократилось число малых и средних предприятий. URL: https://www.vedomosti.ru/business/articles/2020/08/11/836350-v-rossii-sokratilos-chislo-malih-predpriyatii

18. Среднемесячная заработная плата в регионах. URL: https://rosstat.gov.ru/labor_market_employment_salaries

19. Средняя заработная плата работников по видам экономической деятельности. URL: https://rosstat.gov.ru/labor_market_employment_salaries

20. Уровень инфляции в Российской Федерации в 2021 году. URL: https://www. statbureau.org/ru/russia/inflation

21. Падение экономики России из-за пандемии стало максимальным за 11 лет. URL: https://www.rbc.ru/economics/01/02/2021/6017e1819a7947cb98f23f95

22. Россия для мигрантов: зачем нужны «золотые паспорта». URL: https://www.forbes. ru/obshchestvo/403137-rossiya-dlya-migrantov-zachem-rossii-potrebovalis-zolotye-pasporta

23. Эксперты оценили последствия оттока мигрантов из России. URL: https:// www.rbc.ru/economics/03/11/2020/5f9bf5269a794771485ceb51

24. Прогноз социально-экономического развития Российской Федерации на период до 2036 г. URL: http://old.economy.gov.ru/minec/about/structure/depMacro/201828113

118 Bulletin of the Volga Region Institute of Administration • 2021. Vol. 21. № 4 